\title{
UPRAVLJANJE RIZICIMA - TRENDOVI I PRAKSE
}

\section{Bojan Radoš}

VTB Banka a.d., Beograd, Srbija
Korespondencija:

Bojan Radoš

e-mail:

\begin{abstract}
Apstrakt:
Kada govorimo o savremenim uslovima poslovanja, proces poslovnog odlučivanja je neodvojivo vezan za proces upravljanja rizicima. Koliko će sam proces biti razvijen zavisi od podrške rukovodstva organizacije, ali i od regulatornog okvira, ukoliko isti postoji. Prisutan je trend razvoja svesti o procesu upravljanja rizicima i njegovom uticaju na celokupno poslovanje. Takođe, prisutan je trend razmatranja efikasnosti celokupnog sistema upravljanja rizicima od strane interne revizije. Odvojenost regiona i stepen ekonomskog razvoja nije presudan faktor koji utiče na razvoj procesa upravljanja rizicima. Istraživanja pokazuju da sa razvojem veličine organizacije raste i svest o neophodnosti upravljanja rizicima. Kada posmatramo finansijske indikatore, zapaža se da sa većim i značajnijim efektima raste i potreba za upravljanjem imovinom i resursima posredstvom uticaja rizika. Cilj je da željene performanse organizacije oslikavaju njene sposobnosti upravljanja rizicima i prinosne snage na uložena sredstva.
\end{abstract}

Ključne reči:

organizacija, korporativno upravljanje, odlučivanje.

U savremenim uslovima poslovanja organizacije sve više pažnje posvećuju rizicima i njihovom uticaju na celokupno poslovanje. Ovakav trend nije slučajan, niti je nastao kao posledica recesije i njenih efekata na tržištu. Savremeno korporativno upravljanje ga prepoznaje kao vitalnu komponentu u procesu donošenja poslovnih odluka. Poslovno planiranje, strategije i ciljevi direktno se sagledaju kroz rizike i efekte koje oni mogu imati na poslovanje organizacija. Međutim, suštinsko pitanje koje se postavlja u ovom radu jeste na koji način je proces upravljanja rizicima uspostavljen u organizacijama, koliko je razvijen i da li je u mogućnosti da doprinese kvalitetu poslovnih odluka u savremenom korporativnom poslovanju. Da li je stepen organizacione razvijenosti u direktnoj funkciji postojeće regulative i prakse ili je u funkciji veličine same organizacije, samo su neka od pitanja koja se postavljaju u ovom radu. Odgovore treba tražiti u sprovedenim analizama, ali i tendenciji da je kategorija željenih performansi organizacija u direktnoj funkciji njenih rizika i prinosne snage na uložena sredstva i resurse kojima raspolaže.

\section{SHVATANJE RIZIKA I NEOPHODNOST NJEGOVOG UPRAVLJANJA}

Tradicionalna shvatanja unutrašnje kontrole bazirala su se na mišljenju da jedino interna revizija treba da identifikuje negativne tendencije izazvane realizovanim rizicima u poslovanju organizacija. Razvojem korporativnog upravljanja ovo stanovište se promenilo, jer su se i same organizacije menjale i prilagođavale uslovima na tržištu. Takve izmene su zahtevale i primenu drugačijeg načina razmišljanja i odnosa prema rizicima.

Bez obzira na izmene u načinu ophođenja organizacija prema konceptu korporativnog upravljanja, interna revizija ima izuzetno značajnu ulogu u razmatranju sveobuhvatnosti sistema upravljanja rizicima organizacije. Naravno, pod uslovom da je 
uspostavljen formalan proces upravljanja istim. U suprotnom, predstoji borba koja će omogućiti da se razume suština korporativnog upravljanja, njegovi sastavni elementi i uloga u ostvarivanju postavljenih ciljeva.

Posmatrajući trendove koji su definisani kao segment najbolje poslovne prakse, interna revizija umesto primarne uloge identifikovanja nedostataka i pretnji po organizaciju, zauzima tek treće mesto u sistemu odbrane. Ovo stanovište zasnovano je na konceptu "tri linije odbrane" (The Three Lines of Defense Model), koji predstavlja svojevrstan odgovor na izazove koje je recesija donela sa sobom. Kada govorimo o formalanom procesu upravljanja rizicima, model "tri linije odbrane" pozicionira ulogu svih faktora u organizaciji. Kao takav, ovaj model jasno definiše ulogu i odgovornost menadžmenta za upravljanje rizicima, ulogu ostalih organizacionih jedinica, kao i samu internu reviziju.

Slučajno ili namerno, posebnu pažnju treba posvetiti stanovištu po kojem je ovaj sistem svojstven celokupnom korpusu upravljanja organizacijom. Potrebno je naglasiti da se uloga interne revizije ogleda u njenoj misiji da doprinese unapređenju, kao i da osigura uspostavljene vrednosti organizacije koje su zasnovane na adekvatnosti upravljanja rizicima, objektivnosti, pouzdanosti uveravanja, savetovanju i shvatanju. Posledice recesije iz 2008. godine, koje se još uvek osećaju, intenziviraju značaj osiguranja uspostavljenih vrednosti organizacije.

Brojne respektabilne institucije sprovele su istraživanja na temu upravljanja rizikom, pre svega istraživanja koja su sprovele sledeće institucije: COSO's 2010 Report on ERM (COSO, 2010); 2011 Enterprise Risk Benchmark Survey (RIMS, 2011), 2011 Global Survey on Risk Management and Internal Control (IFAC, 2010). Takođe, tokom 2015. godine CBOK je sproveo istraživanje na temu upravljanja rizicima.

CBOK je u istraživanju postavio ključno pitanje: da li postoji uspostavljen sistem upravljanja rizicima i kakva je njegova efektivnost? Recesija je sasvim jasno ukazala da se pitanju upravljanja rizicima i riziku kulture poslovanja mora posvetiti značajnija pažnja, kako bi se upravljalo organizacijom. Analize na ovu temu potvrdile su da je sistem upravljanja rizicima u svome kontinuiranom razvoju na globalnom planu, a recesija je sa svoje strane doprinela unapređenju regulativa. Takođe, kroz iskustva upravljanja rizikom nastali su brojni tekstovi, koji su doprineli unapređenju upavaljanja rizikom.

CBOK analiza iz 2015. godine ukazuje na činjenicu prema kojoj Evropa iskazuje veći procenat prisustva formalno uspostavljenog procesa upravljanja rizicima od ostalih regiona sveta. Potvrdan odgovor dalo je čak 67\% ispitanika (Tabela 1). Kada je u pitanju adekvatnost upravljanja rizicima, evropsko unapređenje regulative podržalo je ovaj trend. Indikativno je da analiza pokazuje da upravo finansijski sektor ima dominantnu ulogu, kada je u pitanju formalno uspostavljanje funkcije upravljanja rizicima i ocena njene adekvatnosti na globalnom nivou.
Tabela 1. Razvijenost formalnog procesa upravljanja rizicima po regionima u procentima

\begin{tabular}{lcccc}
\hline \multicolumn{1}{c}{ REGION } & Nije & $\begin{array}{c}\text { Nije for- } \\
\text { malno us- } \\
\text { postavljen/ } \\
\text { u procesu } \\
\text { dizajniranja }\end{array}$ & $\begin{array}{c}\text { Uspostav- } \\
\text { form je } \\
\text { formalni } \\
\text { proces } \\
\text { urvaljanja } \\
\text { rizicima }\end{array}$ & $\begin{array}{c}\text { Uspostavljen je } \\
\text { formalni proces } \\
\text { upravljanja rizicima } \\
\text { na pozicijo je lice } \\
\text { Direktor Sektora } \\
\text { upravljanja rizicima }\end{array}$ \\
\hline Evropa & 7 & 27 & 33 & 34 \\
\hline Pod Saharski region & 10 & 36 & 32 & 21 \\
\hline Severna Amerika & 4 & 44 & 25 & 27 \\
\hline Južna Azija & 4 & 45 & 37 & 14 \\
\hline $\begin{array}{l}\text { Istočna Azija i } \\
\text { Pacifik }\end{array}$ & 14 & 38 & 31 & 17 \\
\hline $\begin{array}{l}\text { Latinska Amerika i } \\
\text { Karibi }\end{array}$ & 17 & 40 & 25 & 17 \\
\hline $\begin{array}{l}\text { Bliski Istok i } \\
\text { Severna Afrika }\end{array}$ & 20 & 45 & 23 & 12 \\
\hline Globalni prosek & 10 & 37 & 29 & 24 \\
\hline
\end{tabular}

Posmatrano prema karakteru industrijskih grana, finansijski sektor i osiguranje ima 74\% uspostavljenosti formalnog sistema upravljanja rizicima (Tabela 2). Ovo nije neko iznenađenje, ako se zna da je finansijski sektor snažno podržan regulativom. Ako bismo komparativno poredili rezultate, možemo uočiti da u odnosu na naše prilike ne postoje bitnije razlike, jer je i u našoj zemlji zakonska regulativa kojom se definiše proces upravljanja rizicima dominantna za finansijski sektor.

Tabela 2. Razvijenost formalnog procesa upravljanja rizicima po industrijskim granama u procentima

\begin{tabular}{lc}
\hline Industrijska grana & Procenat \% \\
\cline { 1 - 1 } Globalni prosek 53\% & 74 \\
\hline Finansijski sektor i osiguranje & 56 \\
\hline Rudarstvo,nafta i gas & 56 \\
\hline Komunalne usluge & 55 \\
\hline Naučno istrǎ̌ivačka delatnost & 49 \\
\hline Gradjevinarstvo & 47 \\
\hline Veletrgovina & 46 \\
\hline Javna administracija & 45 \\
\hline Zdravstvo & 44 \\
\hline Proizvodna delatnost & 42 \\
\hline Trgovina na malo & 31 \\
\hline Obrazovni sistem &
\end{tabular}

Potrebno je naglasiti da u kumulativnom pogledu, posmatranom na nivou svih ostalih industrijskih grana, procentualna zastupljenost postojanja formalnog procesa upravljanja rizicima van finansijskog sektora iznosi oko $45 \%$ na globalnom nivou (Tabela 3). 
Tabela 3. Praksa upravljanja rizicima u finansijskom i nefinansijskom sektoru

\begin{tabular}{lcc}
\hline \multicolumn{1}{c}{ Praksa upravljanja rizicima } & $\begin{array}{c}\text { Finansijski } \\
\text { sektor }\end{array}$ & $\begin{array}{c}\text { Nefinansijske } \\
\text { industrije }\end{array}$ \\
\hline Proces nije uspostavljen & 3 & 13 \\
\hline $\begin{array}{l}\text { Proces još uvek nije formalizovan ili } \\
\text { je u fazi dizajniranja }\end{array}$ & 23 & 42 \\
\hline $\begin{array}{l}\text { Formalan proces uspostavljen i efek- } \\
\text { tivan u primeni }\end{array}$ & 74 & 45 \\
\hline
\end{tabular}

Razlog za ovako slab procenat identifikovan je u nedostat$\mathrm{ku}$ regulative $\mathrm{u}$ industrijskim granama, koja bi primorala organizacije da je primene. Ukoliko se posmatra na ovaj način, takav trend se može uočiti i kod nas. Sprovedenim analizama profilisan je detalj koji ukazuje da je prisutnost upravljanja rizicima evidentnija kod velikih pravnih lica, za razliku od malih i srednjih organizacija. Formalizovan proces upravljanja rizicima prisutan je u 7 od 10 velikih organizacija, dok je taj odnos kod malih i srednjih organizacija 4 od 10. Razlog za ovakvo stanovište može se pronaći u činjenici da velike organizacije imaju veću potrebu i veće resurse za upravljanje rizicima, i da su finansijske institucije velike po svojoj segmentaciji, tako da direktno učestvuju u ovakvom trendu.

Posmatrano prema veličini ostvarenih prihoda na godišnjem nivou, evidentno je da kako se ova bilansna pozicija povećava, tako se povećava i procenat prisutnosti formalno uspostavljenog procesa upravljanja rizicima u organizacijama. Iako se naše kompanije ne mogu porediti u ovoj kategoriji, očigledno je da organizacije koje na globalnom nivou ostvaruju veće prihode (100 miliona USD) imaju stabilan trend povećanja procenta prisutnosti formalnog procesa upravljanja rizicima.

Za organizacije koje ostvaruju preko 10 milijardi USD procenat se kreće do 73\%. Kod organizacija koje ostvaruju prihode do 1 miliona USD ovaj procenat se na globalnom nivou pozicionira na oko $46 \%$, što ukazuje da gotovo svaka druga organizacija ima uspostavljene mehanizme za upravljanje rizicima.

Možemo zaključiti da finansijske institucije, kao i velike kompanije, prikazuju veću potrebu za unapređenjem formalnog procesa upravljanja rizicima. Isto tako, u odnosu na ostatak sveta, evropske organizacije više primenjuju poces upravljanja rizicima koji je pre svega podržan usvojenom, ali i unapređenom, regulativom po pitanju upravljanja rizicima. Ipak, treba primetiti da i u drugim delovima sveta postoji regulativa koja podržava ovo pitanje. Tu pre svega mislimo na US Sarbanes-Oxley zakon iz 2002. godine, ali da bi se regulative primenjivale u celini neophodno je unapređenje procesa upravljanja rizicima.

Umesto integralnog sagledavanja procesa, akcenat se stavlja na uticaj rizika na pojedinačne segmente. Pre svega, ukazuje se na značaj sistema internih kontrola za potrebe finan- sijskog izveštavanja. Sa druge strane, moramo naglasiti da se fokus pomera sa isključivosti i dominacije finansijskog izveštavanja na adekvatnost nefinansijskog izveštavanja i njegov doprinos sveobuhvatnom razumevanju korporativnog upravljanja organizacijama. Ističe se prisutnost Direktive 2014/95/ EU koja se bavi ovim pitanjem i pozicioniranjem primene ovih pravila na organizacije koje imaju preko 500 zaposlenih i koje su segmentirane kao velike organizacije.

Takođe, u zaključku ove analize navodi se da proces upravljanja rizicima na globalnom nivou još uvek nije prepoznat u $47 \%$ organizacija, što ukazuje na nedostatak regulative ili nespremnost organizacija da uspostave ovaj proces (Tabela 4). Postavlja se pitanje: da li postoje interno razvijeni mehanizmi koji mogu doprineti afirmaciji sistema upravljanja rizicima? Naravno, odgovor se može tražiti u funkciji interne revizije i prirodi njenog posla, kao i u dijalogu između zainteresovanih strana: organizacije, menadžmenta i interne revizije.

Tabela 4. Formalizovanost procesa upravljanja rizicima

\begin{tabular}{lc}
\hline \multicolumn{1}{c}{ Pitanje } & $\begin{array}{c}\text { Vrednost } \\
\mathrm{u} \%\end{array}$ \\
\hline $\begin{array}{l}\text { Uspostavljen je formalni proces upravljanja rizicima } \\
\text { i angažovano je lice na poziciji CRO - Direktor Sek- } \\
\text { tora upravljanja rizicima }\end{array}$ & 24 \\
\hline
\end{tabular}

Uspostavljen je formalni proces upravljanja rizicima 29

Nije formalno uspostavljen/ u procesu dizajniranja 37 Nije 10

Dijalog treba da bude usmeren na ciljeve organizacije i raspoložive resurse koje organizacija ima i koje želi da ostvari. Od ključnih strana u ovom procesu se očekuje da daju uputstvo o načinu na koji će se profilisati rad same organizacije. Treba naglasiti da ovo nije samo proces koji treba staviti na papir, već živ sistem koji je potrebno svakodnevno analizirati i nadgledati. Postoje brojne preporuke na ovu temu, ali one koje bi na prvom mestu mogle da pomognu su: iniciranje dijaloga, razmatranje sistema upravljanja rizicima i razmatranje njegove uloge u organizaciji i njenom poslovanju. Postizanje ciljeva uz poštovanje uspostavljene sklonosti ka riziku (risk appetite) je standard koji se želi ostvariti. Trebalo bi izbegavati isključivost pojedinca, koja je naročito izražena u organizacijama u kojima vlada pravilo ključnog čoveka (key man) u domenu donošenja poslovnih odluka. Druga preporuka se odnosi na traženje prilika sa ciljem da se pomogne implementaciji sistema upravljanja rizicima, i da se ubrzaju postupci njegove primene u praksi. Treća preporuka se odnosi na rukovodioce službi u organizaciji, i ostalim pružaocima uveravanja ako postoje, sa ciljem jasne determinisanosti uloga i odgovornosti svih činilaca u sistemu "tri linije odbrane" u organizaciji. 
DA LI POSTOJI ODGOVORNOST UPRAVLJANJA RIZICIMA U KORPORATIVNOM POSLOVANJU?

Trendovi savremenog korporativnog poslovanja ukazali su na stav da je neophodno imati jasnu odvojenost funkcija upravljanja rizicima i interne revizije. Međutim, bitno je naglasiti u kojoj meri i sa kakvim mišljenjima interna revizija koncipira svoje stavove, kada je u pitanju uveravanje i savetovanje menadžmenta o rizicima i upravljanju rizicima.

$\mathrm{U}$ ovom domenu treba zasebno razmatrati dva pravca. Jedan koji se odnosi na davanje mišljenja koje se odnosi na celokupnost uspostavljenog sistema upravljanja rizicima, odnosno drugi pravac koji se odnosi na davanje mišljenja o efektivnosti upravljanja pojedinačno identifikovanim rizicima po poslovanje organizacije. Na osnovu analiziranog uzorka, utvrđeno je da je na globalnom nivou svega $47 \%$ ispitanika potvrdilo da se uveravanje kao i savetodavne preporuke daju za sisteme upravljanja rizicima u celosti (Tabela 5). U odnosu na ispitivanja koja su sprovedena tokom 2010. godine, može se zaključiti da je trend u neznatnom opadanju. Sa druge strane, istraživanje je usmereno na teren pojedinačnih rizika i njihov uticaj na organizaciju.

Tabela 5. Procenat uveravanja o procesu upravljanja rizicima

\begin{tabular}{lc}
\hline \multicolumn{1}{c}{ Pitanje } & $\begin{array}{c}\text { Vrednost } \\
\mathrm{u} \%\end{array}$ \\
\hline $\begin{array}{l}\text { Uveravanje u celokupan proces upravljanja } \\
\text { rizicima }\end{array}$ & 47 \\
\hline $\begin{array}{l}\text { Uveravanje u pojedinačne rizike } \\
\text { Savetovanje i konsultacije }\end{array}$ & 44 \\
\hline $\begin{array}{l}\text { Ne primenjuje pristup uveravanja zasnovan na } \\
\text { upravljanju rizicima }\end{array}$ & 7 \\
\hline $\begin{array}{l}\text { Ostale tehnike i metodi } \\
\end{array}$ & 6 \\
\hline
\end{tabular}

Kada govorimo o uveravanjima u celini najznačajniji trend je prisutan u regionu Južne Afrike (Pod-Saharski region), koji učestvuje sa $60 \%$ ispitanika i kao takav ima globalno najviši trend. Ova konstatacija proizvod je snažne regulative koja je profilisana na temu korporativnog upravljanja organizacijama.

Iako ima regulatorni okvir, Evropa je na drugom mestu sa učešćem od 57\%. Severna Amerika učestvuje sa $44 \%$ pružanja uveravanja u celosti, dok ostali regioni imaju manju procentualnu vrednost, što pokazuje da uveravanje u celosti još uvek nema preovlađujući trend. Sa druge strane, obaveza razmatranja sistema upravljanja rizicima kroz SOX regulative, u značajnijoj meri zaokuplja pažnju, pre svega kada se radi o regionu Severne Amerike. U domenu segmentacije organizacija, ovde je trend ne promenjen, velike organizacije se po pravilu više bave pitanjem uveravanja sistema upravljanja rizicima u celosti. Mišljenja smo da upravo mala i srednja preduzeća, koja insistiraju na jačanju unutrašnjih vrednosti privrednog ambijenta, predstavljaju idealan prostor za afirmaciju koncepta korporativnog upravljanja zasnovanog na upravljanju rizicima, i učešću funkcije interne revizije u pružanju uveravanja i savetovanja o procesu upravljanja rizicima.

Potrebno je naglasiti da se za ovakvu vrstu uveravanja i savetodavnih aktivnosti moraju precizno formulisati kriterijumi na osnovu kojih će se isti razmatrati. Kriterijumi mogu da variraju od regiona do regiona, kao i između industrijskih grana. Sa druge strane, postavlja se pitanje da li postoji prostor oko regulatornog okvira, odnosno da li se primenjuju postojeće prakse? Trend pokazuje da je na globalnom nivou $53 \%$ ispitanika potvrdilo da u svojim sredinama ima formalno uspostavljen sistema upravljanja rizicima, dok $47 \%$ ispitanika vrši uveravanja u vezi sa celokupnim sistemom upravljanja rizicima. Ova razlika ukazuje da, i pored uspostavljenog formalnog okvira, nivo uveravanja nije dostigao veličinu koja odgovara nivou uspostavljenog procenta formalnog sistema upravljanja rizicima, što govori o tome da ima prostora za unapređenje uveravanja.

Ako razlike industrijskih grana sagledamo na globalnom nivou, dobijamo interesantne podatke o njihovim trendovima. Ne postoji industrijska grana gde je prisutan veći stepen uveravanja u odnosu na formalno uspostavljen model upravljanja rizicima. Sa druge strane, industrijske grane sa najvećim procentom prisutnosti formalne uspostavljenosti sistema za upravljanje rizicima (finansijski sektor, kao i komunalne usluge), nalaze se u vrhu identifikovanih razlika, između formalno uspostavljenog sistema i nivoa uveravanja $\mathrm{u}$ isti. Finansijski sektor ima identifikovanih 13\%, dok komunalne usluge imaju $17 \%$, što je značajno u odnosu na globalni prosek od 7\%.

Kod ostalih, za nas značajnih industrijskih grana, odnos po ovom pitanju je u sledećim razmerama: građevinarstvo $16 \%$; trgovina na veliko $14 \%$; javna administracija $10 \%$; tržište nekretninama 9\%; zdravstvo 7\%; proizvodnja 5\%; rudarstvo, ostala iskopavanja ruda, naftna industrija i gas $3 \%$. Na osnovu navedenih podataka, predložemo da funkcija interne revizije u svojim godišnjim planovima treba da posveti više vremena za potrebe davanja mišljenja na celokupnost sistema upravljanja rizicima. U domenu pružanja uveravanja na pojedinačnoj osnovi, prisutan je iznenađujuće nizak trend od svega $44 \%$ ispitanika. U ovom domenu nisu prisutna značajnija odstupanja od prethodno razmatranog trenda. U domenu savetodavnih aktivnosti trend pokazuje svoju prisutnost u svega 57\% uzorka. Mišljenja smo da je ovo nizak procenat, posmatrano sa stanovišta njegove važnosti u savremenim uslovima poslovanja i zahtevima koji se stavljaju pred organizacije.

Opravdanost za ovaj trend se traži u činjenici da se uveravanje u rizike na pojedinačnoj osnovi, kao i savetovanje po istom, shvata odvojeno od pitanja uveravanja u sistem upravljanja rizicima u celini. Drugi razlog leži u pitanju, da 
li sami revizori imaju dovoljno stručnog znanja za pojedine segmente poslovanja organizacija kako bi bili u mogućnosti da u celosti pružaju svoje savetodavne usluge menadžementu. Posmatrano kroz godišnje planove interne revizije na globalnom planu, trend ukazuje da se tema celokupnog uveravanja u sistem upravljanja rizicima kreće oko 12\% ukupnog vremena. Ovde je prisutan uzlazni trend, u odnosu na period 2010 godine kada je bio oko 5\%. Isto tako, ovo je treća najznačajnija vrsta angažmana u vezi sa rizicima koja se nalazi u godišnjim planovima interne revizije. Sa druge strane, prisutni su angažmani za pojedinačne kategorije rizika, tako da iste ublažavaju identifikovani trend. Svoje najznačajnije prisustvo imaju angažmani posvećeni operativnim rizicima koji učestvuju sa $24,5 \%$; rizik usklađenosti sa $15 \%$; strateški poslovni rizici sa $10,8 \%$; korporativno upravljanje sa $6,2 \%$. Što se tiče Evrope kojoj i naša zemlja pripada, trendovi se kreću u sledećim procentima, operativni rizik sa $24,4 \%$, rizik uskladjenosti $14,3 \%$, celokupno uveravanje u sistem upravljanja rizicima $14,2 \%$, strateški poslovni rizici 10,9\%, korporativno upravljanje $6,9 \%$, prevarne radnje 4,0\% i sl. Posebno pitanje koje je obuhvaćeno ovom analizom odnosi se na kombinovana uveravanja unutar samih organizacija.

Postavlja se pitanje da li organizacije imaju na raspolaganju ovaj mehanizam, odnosno da li je on prepoznat kao korist za menadžement i organizaciju? Naravno, suštinsko pitanje je da li interna revizija ima na raspolaganju resurse za celokupno uveravanje kada je u pitanju formalni sistem upravljanja rizicima? Evidentan je trend koji ukazuje da je kod jednog od četiri ispitanika (iz posmatranog uzorka) prisutan neki od modela kombinovanog internog uveravanja. Konkretno, 19\% ispitanika navodi da je primenilo neki formalni oblik kombinovanog uveravanja. Indikativno je da je model sam po sebi kreiran, ali da još uvek nije formalno usvojen od strane uprave organizacije. Ostaje pitanje njegove implementacije i procene efektivnosti u praksi. Preporučuje se aktivnost identifikacije mogućnosti za uspostavljanje kombinovanog internog uveravanja, kao i područja u kojima bi ista mogla da se identifikuje i primeni. Kao osnov za ovakvu tvrdnju navodi se stanovište po kojem će se integralni proces uveravanja podići na viši nivo, pa samim tim i stvoriti veći nivo dodatne vrednosti za organizaciju.

Relevantna je činjenica prema kojoj u modelu "tri linije odbrane", kod 66\% ispitanika (iz uzorka) je prisutna razmena informacija sa sektorom za upravljanje rizicima, ali je prisutan i gap nivoa uveravanja u odnosu na procenat potvrde uspostavljenosti formalnog sistema upravljanja rizicima, što ukazuje na prostor koji treba iskoristiti i unaprediti. Kao i u ostalim analizama, i po ovom pitanju, evidentan je trend po kojem je prisutnost kombinovanog uveravanja češći kod velikih organizacija. Bez obzira na veličinu i regionalnu određenost, kombinovano interno uveravanje nije prisutno $\mathrm{u}$ procentu većem od 36\%. Ovaj trend ukazuje na to da je kombinovano uveravanje u fazi razvoja i da se očekuju dalji efekti na njegovom unapređenju.

Prisutnost regulatornog okvira pokazuje isti trend. Ukoliko postoji regulatorni okvir, onda i sam region ima značajnije učešće u ukupnoj statistici. Kao rezultat uspostavljene regulative, Južna Afrika ima značajno učešće (King III - King report on Corporate Governing) od 41\% uzorka. Najveće razlike između formalno uspostavljenog sistema upravljanja rizicima i prisutnosti kombinovanog internog uveravanja imaju Severna Amerika 31\% i Evropa sa 30\%. Razlog se može tražiti u činjenici da kombinovano uveravanje još uvek nije dostiglo željeni nivo u odnosu na postojeći nivo ukupnog uveravanja sistema upravljanja rizicima. Rezultati ukazuju na mogućnosti da se $\mathrm{u}$ narednom periodu više pažnje posveti ovom pitanju, kako bi kombinovano uveravanje dobilo svoj prostor za afirmaciju.

\section{ZAKLJUČAK}

Uvažavajući podatke navedene u ovom radu možemo zaključiti da se pitanju upravljanja rizicima pridaje sve veći značaj. Poređenje sa analizom sprovedenom 2010. godine to svakako potvrđuje. Sam proces, kao i njegov razvoj, u velikoj meri zavise od regulatornog okvira i njegove razvijenosti. Praksa ne daje uvek željeni rezultat, jer zavisi od samih organizacija i njihove spremnosti da se samostalno razvijaju u ovom pravcu. Isto tako, sprovedena analiza pokazuje da je prisutnost upravljanja rizicima veća ukoliko se radi o velikim organizacijama. Kod malih i srednjih organizacija ovaj trend nije tako dominantan, ali se na osnovu njega može videti na koji način se već u ranoj fazi razvoja implementira ovaj proces.

U ovom radu došli smo do zaključka da je proces upravljanja rizicima sastavni deo savremenog korporativnog poslovanja i da je isti podržan od strane menadžmenta i funkcije interne revizije. Takođe, uočeno je da je u finansijskom sektoru najrazvijeniji proces upravljanja rizicima, ali da je isti proizvod snažne regulative koja postoji širom sveta.

Analiza govori o tome da je i dalje potrebno ulagati u ovaj proces, jer isti nije svuda podržan i nisu jasno identifikovane njegove upotrebne vrednosti po poslovanje organizacija. Potrebno je unaprediti dijalog zainteresovanih strana, poslovanje organizacija, ali i privredni ambijent. Analiza je pokazala da nepostoje jasne razlike po geografskim regionima i da, bez obzira na ekonomsku razvijenost regiona, postoje fluktuacije kada je u pitanju njegova primena. Kada je celokupan sistem upravljanja rizicima u pitanju, broj revizorskih angažmana u domenu uveravanja se procentualno uvećava. Kao takav, sistem upravljanja rizicima predstavlja solidnu osnovu za dalju afirmaciju i podršku korporativnom upravljanju i njegovom usmeravanju ka stvaranju dodate vrednosti za organizacije. 
Cobel, P.J. (2015). Who owns the risk? Preuzeto 11.01.2016. sa http://www.theiia.org/goto/CBOK

COSO. (2010). COSO's 2010 Report on ERM. Preuzeto 11.01.2016. sa http://www.coso.org/documents/cososurveyreportfull-web-r6finalforwebposting111710.pdf

IFAC. (2011). Global Survey on Risk Management and Internal Control. Preuzeto 11.01.2016. sa https://www.ifac.org/ publications-resources/global-survey-risk-managementand-internal-control

RIMS. (2011). Enterprise Risk Management Survey. Preuzeto 11.01.2016. sa https://www.rims.org/Sales/Documents/ RIMS\%202011\%20ERM\%20Benchmark\%20Survey\%20 final.pdf

\title{
RISK MANAGEMENT, TRENDS AND PRACTICES
}

\begin{abstract}
:
When it comes to modern business conditions, the process of business decision-making is inseparably linked to the process of risk management. How will the process be developed depends on the support of the leadership of the organization, but also on the regulatory framework, if it exists. There is a constant development of awareness of the risk management process and its significance to the overall business. Also, there is a trend of considering and providing assurances by the internal audit about the effectiveness of the entire risk management system. The geographical separation of the region and its economic power are not a crucial factor of development of the risk management process. Trends show that with the growth of the size of the organization, grows the awareness of the necessity of risk management. Also, according to the financial indicators, the higher and more significant the effects are, there is a growing need to manage assets and resources using a risk impact. The objective to be achieved is that the desired performance of the organization reflects its risk management capabilities and yields power to the funds invested.
\end{abstract}

\section{Keywords:}

organization, corporative management, decision-making. 